\title{
Study of the electrical activity of muscles: Masseter, temporal and supra-hyoid during swallowing
}

\author{
Luciana Escanoela Zanato, Brasilia Maria Chiari, Marilena Manno Vieira and Silvana Bommarito \\ Departamento de Fonoaudiologia, Universidade Federal de São Paulo, São Paulo, Brazil
}

\begin{abstract}
Objective: To characterize the electrical activity of the muscles: temporal (anterior portion), masseter and suprahyoid muscles during swallowing and to analyze the difference between the sexes.

Methods: 61 electromyographic examinations were performed. Among the exams evaluated, 40 individuals (65.6\%) were female and 21 (34.4\%) were male. The mean age of the volunteers was 23.77 years with standard deviation (SD) of +/- 6.44 years. The muscles: temporal (anterior portion), masseter and suprahyoid muscles were evaluated bilaterally in the following tests: habitual rest and swallowing of $10 \mathrm{ml}$ of water. The Mann-Whitney test was used to verify the difference between the sexes. The significance was $5 \%(\mathrm{p}<0.05)$.

Results: The results of this study demonstrated that there is a greater participation of the suprahyoid muscles during swallowing, not excluding the participation of the masseter and temporal muscles (anterior portion). During water swallowing, there was participation of the temporal (anterior portion), masseter and especially of the suprahyoid muscles. In the comparison to activity in the male and female sexes, during rest and swallowing, there was greater electrical activity for the female sex.

Conclusion: During the swallowing of water there was participation of the temporal muscles (anterior portion), masseter and mainly of the suprahyoid muscles. In the comparison of activity in the male and female sexes, during rest and swallowing, there was greater electrical activity in the female sex.
\end{abstract}

\section{Introduction}

Swallowing results from a complex, dynamic neuromotor mechanism, fundamental for nutrition and hydration. This act aims to transport the food bolus from the mouth to the stomach efficiently and effectively [1,2]. Didatically, it can be divided into the following phases: anticipatory $[3,4]$, preparatory-oral and oral - voluntary; Pharyngeal and esophageal - voluntary [5].

There have been many attempts to evaluate the activity of the muscles during this complex process, in which as surface electromyography (EMGs) is one of them and consists of a diagnostic device that involves the detection and Electrical potentials of skeletal muscle fibers.

In EMGs, the electrodes are positioned in the muscles of interest, they pick up this electrical signal and transform it into visual signals, which will be interpreted by the examiner. Thus, it is possible to know when and how a muscle is activated and, also, to determine how the coordination of different muscles involved in movements is established [6].

The EMGs, being a non-invasive, painless, simple and reproducible procedure, can be easily performed by a properly trained professional in a specific laboratory and has proved to be a valuable tool for the study of swallowing physiology as well as in the treatment and description of maneuvers [7-9] and also to confirm the activation of the musculature that one wishes to recruit in certain tasks $[9,10]$, being able to evaluate swallowing in different consistencies [11].

It is known that the supra-hyoid muscles (myohyoid, geniohyoid, digastric and hyoid-style) and tongue muscles are the main representative muscles that are important for swallowing. Little is known about the performance of other muscles of the stomatognathic system during swallowing, however [12].

The temporal muscle is one of the muscles of the stomatognathic system that has the function of elevating the mandible, closing the mouth, which makes it to be considered a positioning muscle of the mandible, whereas the masseter muscle, as well as the temporal muscle, has the function of elevation of the jaw, closing the mouth. The masseter muscle contributes very little to the protrusion of the mandible, being considered a force-generating muscle, however. The suprahyoid muscles have the function of lowering the mandibular against resistance when the infra-hyoid muscles fix or depress the hyoid bone [13]. Although pioneering studies were initiated in the 1950s [14], few studies have aimed to study only normal electrophysiological behavior, so the objective of this study was to characterize the electrical activity of the muscles: temporal (anterior portion), masseter and suprahyoid muscles during swallowing, and analyze the difference between the sexes.

\section{Method}

The electromyographic examination was performed in 61 individuals, with no complaint of swallowing abnormalities. Among

Correspondence to: Silvana Bommarito, Departamento de Fonoaudiologia, Universidade Federal de São Paulo, Rua Botucatu, 802 São Paulo 04023-062, São Paulo, Brazil, E-mail: bomarito@terra.com.br

Key words: surface electromyography, muscles, anatomy, swallowing

Received: December 10, 2016; Accepted: December 20, 2016; Published: December 23, 2016 
the exams evaluated, 40 individuals (65.6\%) were female and 21 (34.4\%) were male. The mean age of the volunteers was 23.77 years with standard deviation (SD) of $+/-6.44$ years. All the sample participants signed the Free and Informed Consent Term (FICT), authorizing their participation in research projects at the institution under the protocol number: $81620 / 12$. The inclusion criteria of the study were: all components presented permanent dentition, stable occlusion and no dental mutilation. Exams were excluded from individuals with malformation syndromes or who had undergone any type of orthognathic surgery or who reported temporomandibular dysfunction or functional habits during the anamnesis, such as dental tightening, bruxism, onicophagy. Individuals who reported using medications that could interfere with muscle activity were also excluded, as well as directly or indirectly, such as: antihistamines, sedatives, muscle relaxants, and or other drugs depressants of the Central Nervous System.

\section{Experiment}

The muscles analyzed with EMGs were right and left masseters, right and left anterior temporals, and right and left suprahyoid muscle groups.

EMG signals were obtained using an eight-channel apparatus K6-1 Diagnostic System from Myo-Tronics (Washington, USA) and Scan \# 10 software from the same system.

The signal picked up by the electrodes was amplified 2000 times and filtered with bandpass filters from 20 to $500 \mathrm{~Hz}$ and common module rejection $>120 \mathrm{~dB}$.

Participants were instructed to remain seated in a chair, separated feet, relaxed shoulders and hands resting on thighs, with head on the Frankfurt parallel to the ground. It was not possible for the participant to observe the signal on the computer screen. The skin of the subjects was cleaned with cotton soaked in $70 \%$ alcohol in order to decrease the impedance between the skin and the electrodes. The electrodes used were bipolar, self-adhesive silver $(\mathrm{Ag} / \mathrm{Agcl})$ surfaces, trademark H.A.L. Industry \& Commerce, with size of $4 \mathrm{~cm} \times 2.2 \mathrm{~cm}$. Each pole was $1 \mathrm{~cm}$ in diameter with a distance of $2 \mathrm{~cm}$ between the poles. The electrodes were positioned in each muscle evaluated, and the fixation occurred by the adhesives constituting them. To guarantee the correct positioning of the electrodes, each study participant was asked to perform a dental tightening with maximum force. In the masseter muscle, the electrode was fixed at the point of greatest volume. In the anterior temporal muscle, the fixation site was determined by an imaginary oblique line from the pupil to the angle of the mandible, and the fixation site of the electrodes was approximately two to three centimeters from the lateral corner of the eyes of a region devoid of hair. And finally, in the suprahyoid muscles the electrodes were fixed parallel to the muscle fibers immediately after saliva swallowing.

The evaluations were performed during the individual usual rest and swallowing $10 \mathrm{ml}$ of fine liquid (water). Prior training was given to familiarize the participants with the requested tests. Signals were recorded twice for 10 seconds each and 3-minute interval between readings.

Each individual received detailed instructions on the procedures to be performed, consisting of the following steps:

Rest: The recording of muscle activity at rest aimed at determining the minimum electromyographic activity present in the muscles, in the absence of the movement request, and also to observe possible muscular hyperactivity before activities that have a greater recruitment of muscle fibers.

Liquid swallowing: to the evaluation of swallowing, the individual was instructed to put the liquid into the cavity of the mouth and retain it inside the cavity of the ball and swallow it normally at the command of the evaluator - it was used the volume of $10 \mathrm{ml}$. The liquid was offered to the subjects in disposable plastic cups. After that, the following command is given: "Swallow water normally", the first swallowing is done with the $10 \mathrm{ml}$ of water and, after that, the saliva with the remaining volume of water, if it still exists.

The measures of duration and the amplitude of RMS (root mean square root) of the electromyographic activity during swallowing were made using functions specific to the EMG Diagnostic System. Each stroke is displayed on the monitor screen during the test corresponding to the muscle activity of each muscle, which is simultaneously shown in different colors. Every second the average muscle activity is given and, at the end of the 10 seconds of recording, the program itself provides the arithmetic mean of the muscle activity of each muscle alone.

\section{Statistical analysis}

Statistical analysis was performed using SPSS (StatisticalPackage for Social Sciences) software 20.0 for Windows and specific statistical tests were applied to analyzbe the variables. We adopted the significance level of 5\% (0.050) for the application of these tests. To verify if there is a difference in electrical activity between the sexes, the Mann-Whitney test was applied.

\section{Results}

In order to know the minimal muscle activity of the individuals in the evaluated muscles, it was possible to observe a small activity average, when comparing the mean muscle activity of the temporal, masseter and suprahyoid muscles of the muscles. $4,81(\mu \mathrm{V})$, followed by the suprahyoid muscle and the masseter muscle, There were no statistically significant differences between the means, nor between the left and right side (Table 1).

During the study of the electrical activity during water swallowing it was possible that when we compared the studied muscles, the highest electrical activity was found in the supra-hyoid muscles with values of $9.6(\mu \mathrm{v})$ on the left side and $9.5(\mu \mathrm{v})$ To the right, as was expected

Table 1. Distribution of the values of the electrical activity of the studied muscles during the habitual rest.

\begin{tabular}{|c|c|c|c|c|c|c|}
\hline & \multicolumn{6}{|c|}{ Usual rest } \\
\hline & \multicolumn{2}{|c|}{ Músculo Temporal } & \multicolumn{2}{|c|}{ Músculo Masseter } & \multicolumn{2}{|c|}{ Músculo Supra- Hióideos } \\
\hline & $\mathbf{L}$ & $\mathbf{R}$ & $\mathbf{L}$ & $\mathbf{R}$ & $\mathbf{L}$ & $\mathbf{R}$ \\
\hline Mean & 4,81 & 4,14 & 2,81 & 4,14 & 4,43 & 3,19 \\
\hline Mínimum & 1,11 & 0,91 & 0,91 & 0,70 & 1,40 & 1,30 \\
\hline Máximum & 17,0 & 19,1 & 5,90 & 7,10 & 9,90 & 11,5 \\
\hline SD & 3,27 & 2,91 & 0,98 & 1,57 & 1,61 & 1,83 \\
\hline
\end{tabular}

L Left Side / R - Right Side; SD: Standard deviation 
Table 2. Distribution of the electrical activity values $(\mu \mathrm{V})$ of the muscles studied during the swallowing of $10 \mathrm{ml}$ of water.

\begin{tabular}{|c|c|c|c|c|c|c|}
\hline & \multicolumn{6}{|c|}{ Swallowing of $10 \mathrm{ml}$ of water } \\
\hline & \multicolumn{2}{|c|}{ Músculo Temporal } & \multicolumn{2}{|c|}{ Músculo Masseter } & \multicolumn{2}{|c|}{ Músculo Supra- Hióideos } \\
\hline & $\mathbf{E}$ & D & $\mathbf{E}$ & D & $\mathbf{E}$ & $\mathbf{D}$ \\
\hline Mean & 7,35 & 6,99 & 5,85 & 6,46 & 9,62 & 9,53 \\
\hline Mínimum & 0,70 & 0,90 & 2,20 & 2,50 & 4,40 & 3,30 \\
\hline Máximum & 44,40 & 41,70 & 41,80 & 32,70 & 28,20 & 44,00 \\
\hline SD & 6,992 & 6,06 & 5,12 & 3,99 & 3,88 & 6,25 \\
\hline
\end{tabular}

L Left Side / R - Right Side; SD: Standard deviation

Table 3. Distribution of the mean values, standard deviation and (p) value of the electrical activity $(\mu \mathrm{V})$ in the muscles studied in the sexes during Deglutition of $10 \mathrm{ml}$ of water.

\begin{tabular}{|c|c|c|c|c|c|c|c|c|c|c|c|c|}
\hline \multicolumn{13}{|c|}{ Swallowing of $10 \mathrm{ml}$ of water } \\
\hline & \multicolumn{4}{|c|}{ Muscle Temporal } & \multicolumn{4}{|c|}{ Muscle Masseter } & \multicolumn{4}{|c|}{ Muscles Supra-hióideo } \\
\hline & \multicolumn{2}{|c|}{$\mathbf{L}$} & \multicolumn{2}{|c|}{$\mathbf{R}$} & \multicolumn{2}{|c|}{$\mathbf{L}$} & \multicolumn{2}{|c|}{$\mathbf{R}$} & \multicolumn{2}{|c|}{$\mathbf{L}$} & \multicolumn{2}{|c|}{$\mathbf{R}$} \\
\hline & M & $\mathrm{F}$ & M & $\mathrm{F}$ & M & $\mathrm{F}$ & M & $\mathrm{F}$ & M & F & $\mathrm{M}$ & $\mathrm{F}$ \\
\hline Median & 5,29 & 8,45 & 6,35 & 7,34 & 5,06 & 6,27 & 6,05 & 6,68 & 8,01 & 10,47 & 9,15 & 9,73 \\
\hline SD & 4,09 & 7,94 & 4,86 & 6,64 & 2,35 & 6,09 & 2,17 & 4,70 & 2,55 & 4,40 & 8,31 & 4,97 \\
\hline LS (p) & \multicolumn{2}{|c|}{0,022} & \multicolumn{2}{|c|}{0,439} & \multicolumn{2}{|c|}{0,239} & \multicolumn{2}{|c|}{0,988} & \multicolumn{2}{|c|}{$0,009 *$} & \multicolumn{2}{|c|}{0,149} \\
\hline
\end{tabular}

Left-hand side D- right side M- male Female f SD- standard deviation LS (p) level of significance.

for this study, since the supra-hyoid muscles are elevators of the hóde bone, an essential movement for swallowing. However, it was also possible to observe activity in the jaw lift muscles (temporal muscle anterior portion and masseter) were also activated, when compared to the reference values in the habitual rest evaluation. How can the averages are observed in Table 2.

In the comparison between the sexes it was possible to verify that, in all the studied muscles, the electrical activity was higher in the group of women, except in the temporal muscle (anterior portion) right during the reference values for habitual rest. The highest mean was 5.23 $(\mu \mathrm{V})$ in the left anterior temporalis muscle, the highest mean for males being $4.58(\mu \mathrm{V})$ in the right temporal muscle (anterior portion). There were statistically significant differences for the group of left suprahyoid muscles. During the process of deglutition of $10 \mathrm{ml}$ of water we could observe that the highest averages of muscle activity continued to be in females for all muscles studied. A statistically significant difference was observed in the left anterior temporal (anterior portin) muscles and the left suprahyoid muscles group. The statistically significant difference was maintained during the swallowing of $10 \mathrm{ml}$ of water as can be seen in Table 3.

\section{Discussion}

Swallowing is a continuous process and to be better understood it is diagrammatically divided into phases. These phases involve many structures. The oral manipulation of liquid by means of glass varies significantly, but usually the liquid is manipulated in the oral cavity no more than two to three seconds [13], after the formation of the alimentary bolus the tongue collects and elevates, therefore there is elevation of the jaw and contraction of the lifting muscles (temporal,masseter and lateral pterygoid). However, at this time, the pharyngeal phase of swallowing has not yet started and, therefore, the individual has not yet swallowed, ie, the food was positioned for later ejection. As the jaw lift muscles relax, contraction of the supra-hyoid muscles in general, concomitant with the movements of the tongue. In Table 2, when we analyzed the mean values of the electrical activity $(\mu \mathrm{V})$ of the muscles studied during the swallowing of $10 \mathrm{ml}$ of water, we observed that during this activity (water swallowing) the highest mean was found in the suprahyoid muscles. The electrical activity of the suprahyoid muscles was $9.6(\mu \mathrm{v})$ for the left side and $9.5(\mu \mathrm{v})$ for the right side. The mandibular levator muscles were also activated in comparison to the usual rest. The temporal muscles (left anterior portion) had $7.3(\mu \mathrm{v})$ and $6.9(\mu \mathrm{v})$ right, whereas the masseter muscles were observed averages of $5,8(\mu \mathrm{v})$ on the left side and $6.4(\mu \mathrm{v})$ on the right side. Different authors have described moderate activity of the suprahyoid muscles during swallowing $[15,16]$. Coriolano [17] also evaluated the swallowing of $10 \mathrm{ml}$ of water, both in the suprahyoid muscles and in the masseter muscles, the means found in the study, are different from those found in our study, however, there are similarities with relation The description of electrical activity of the similar to the average masseter muscle also described of the supra-hoideos muscles.

Regarding the electrical activity of the masseter and temporal muscle during swallowing, we know that the temporal muscle is one of the muscles whose function is to raise the mandible and close the mouth, being considered a positioning muscle of the mandible. The masseter muscle, as well as the temporal muscle, has the function of mandible elevation, closing the mouth, however, the masseter muscle contributes very little to the protrusion of the mandible, being considered a force-generating muscle, this role is very important to stabilize the mandible and consequently explain the performance of the masseter muscle during swallowing [12]. In the comparison between the sexes, we observed that there is a trend of greater electrical activity in the muscles evaluated for females, with a statistically significant difference between men and women for the left suprahyoid muscle group, as well as for habitual rest. Our data differ from those described by [16-19] although the means of electrical activity during swallowing found by the author is similar to the means described in our study. The author states that there is a difference in muscular contraction when comparing men and women during swallowing, and this is greater in males by approximately $12 \%$ in relation to females. It is worth noting that since EMGs are a non-invasive examination, it does not subject individuals to radiation, it can be an important instrument for speech-language practice. Knowledge of muscle physiology in healthy individuals may contribute to the evaluation of swallowing disorders and provide adequate theoretical support for speech therapy planning.

\section{Conclusion}

During swallowing of fine fluid there was participation of the anterior temporal muscles, masseter and mainly of the suprahyoid muscles. 
In the comparison of activity in the male and female sex, during rest and swallowing, there was greater electrical activity in the female sex.

There is a need for further studies to standardize normative values of the electrical activity of muscles during swallowing.

\section{References}

1. Dantas RO, Aguiar Cassiani R, dos Santos CM, Gonzaga GC, Alves LM, et al. (2009) Effect of gender on swallow event duration assessed by videofluoroscopy. Dysphagia 24: 280-284.[Crossref]

2. Pearson WG Jr, Langmore SE, Yu LB, Zumwalt AC (2012) Structural analysis of muscles elevating the hyolaryngeal complex. Dysphagia 27: 445-451. [Crossref]

3. Vaiman M, Nahlieli O, Segal S, Eviatar E (2005) Electromyography monitorsing of patients with salivary glandediseases. Otolaryngol Head Neck Surg 133: 869-873. [Crossref]

4. Sato K, Nakashima T (2006) Human adult deglutition during sleep. Ann Otol Rhinol Laryngol 115: 334-349.[Crossref]

5. Manda Y, Maeda N, Pan Q, Sugimoto K, Hashimoto Y, et al. (2016)New method of neck surface electromyography for the evaluation of tongue-lifting activity. $J$ Oral Rehabil 43: 417-425.[Crossref]

6. Marchesan IQ. Swallowing-normality. In: Furkim AM. Oropharyngeal Dysphagia. (2004) 2nd ed. Carapicuíba: Pro-spcheeterapyst: p.3-18.

7. Zarzur AP, Duprat AC, Shinzato G, Eckley CA (2007) Laryngeal electromyography in adults with Parkinson's disease and voice complaints. Laryngoscope 117: 831-834. [Crossref]

8. Rahal A, Schmidt Goffi-gomez MV (2009)Electromyographic study of the masseter muscle during dental tightening and habitual mastication in adults with normal dental occlusion. Rev Soc Bras Fonoaudiol 14: 160-164.

9. Sze WP, Yoon W, Escoffier N, Rickard Liow SJ (2016) Evaluating the training effects of two swallowing rehabilitation therapies using surface electromyography - chin tuck against resistance (ctar) exercise and the shaker exercise. Dysphagia 31: 195-205. [Crossref]

10. Crary MA, Carnaby GD, Groher ME (2006) Biomechanical correlates of surface electromyography signals obtained during swallowing by healthy adults. $J$ Speech Lang Hear Res49: 186-193.[Crossref]

11. Wheeler KM, Chiara T, Sapienza CM (2007) Surface electromyographic activity of the submental muscles during swallow and expiratory pressure threshold training tasks. Dysphagia 22: 108-116.[Crossref]

12. Taniguchi H, Tsukada T, Ootaki S, Yamada Y, Inoue M (2008) Correspondence between food consistency and suprahyoid muscle activity, tongue pressure, and bolus transit times during the oropharyngeal phase of swallowing. J Appl Physiol 105: 791799.[Crossref]

13. Jong-Chi Oh (2016)Apilot study of the head extension swallowing exercise: new method for strengthening swallowing-related muscle activity. Dysphagia 31: 680-686. [Crossref]

14. Thexton AJ, Crompton AW, German RZ (2007)Electromyographic activity during the reflex pharyngeal swallow in the pig: Doty and Bosma (1956) revisited. $J$ Appl Physiol 102:587-600.[Crossref]

15. Miura Y, Morita Y, Koizumi H, Shingai T (2009) Effects of taste solutions, carbonation, and cold stimulus on the power frequency content of swallowing submental surface electromyography. Chem Senses 34: 325-331.[Crossref]

16. Widmalm SE, Lillie JH, Ash MM Jr (1988) Anatomical and electromyographic studies of the digastric muscle. J Oral Rehab 15: 3-21. [Crossref]

17. Coriolano MGWS, Lins OG, Belo LR, Menezes DC, Moraes SRA, et al. (2010) Monitoring swallowing with surface electromyography. Revista CEFAC 12 .

18. Siqueira LDA (2011)Electromyographic analysis of the masseter muscles, submandibular infrahyoidosis during swallowing of healthy adult subjects, Sao Paulo.

19. Vaiman M,Eviatar E, Segal S (2004) Evaluation of normal deglutition with the help of rectified surface electromyography records. Dysphagia 19: 125-132.[Crossref]

Copyright: (C2016 Zanato LE. This is an open-access article distributed under the terms of the Creative Commons Attribution License, which permits unrestricted use, distribution, and reproduction in any medium, provided the original author and source are credited. 